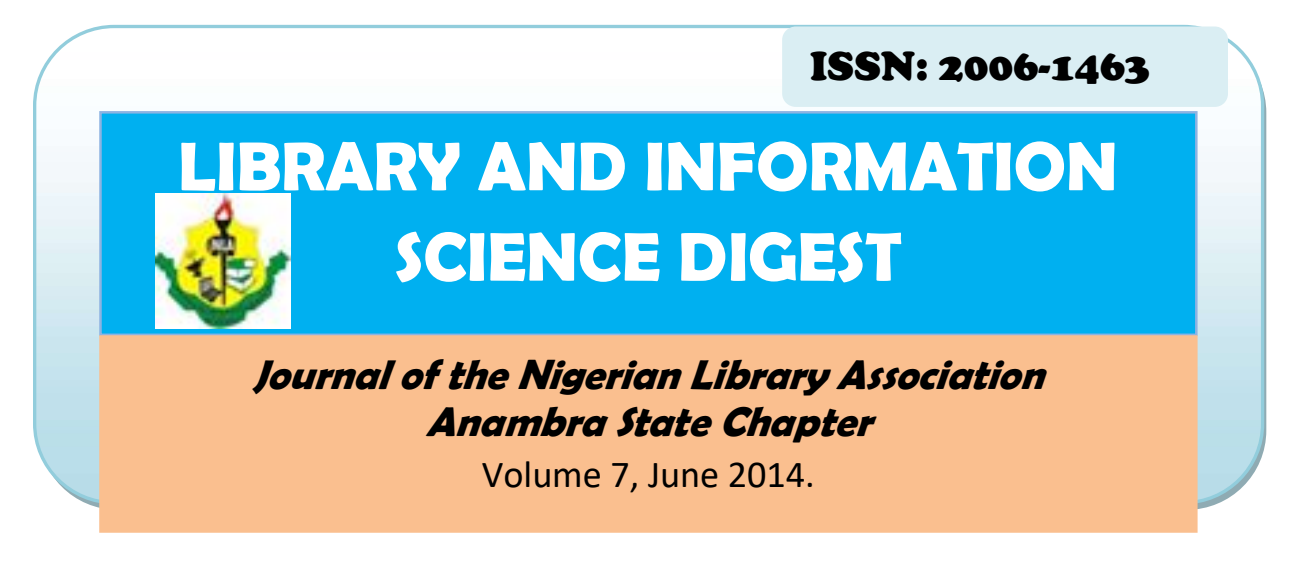

\title{
Article
}

\section{SOCIAL MEDIA AND LIBRARY SERVICES: POINTS OF CONVERGENCE}

\author{
Peter Nnamdi Ibe* \& Obiora Kingsley Udem** \\ *Nnewi Divisional Library, Nnewi
}

**Dept. of Library and Information Science, Nnamdi Azikiwe University, Awka

\begin{abstract}
The Internet has brought in its wake unlimited opportunities for information sourcing, retrieval and dissemination, as well as plethora of platforms for exchange of information. Among such platforms are web 2.0 technologies like Twitter, Blog, Facebook, My space, Linkedin, Wiki, Flicker and a host of others known and referred to as the social media. The social media is home to millions of subscribers who make use of these sites daily for one information need or the other, to socialize or to interact. One of the core mandates of libraries is to provide needed information for their diverse users. Because of the popularity enjoyed by these social media outfits as a result of ability to disseminate information, it has been latched on by many professions, including libraries whose duty is to provide needed information. This paper discusses the major social media technologies and benefits to libraries. It also explained the need for these social media technologies in the libraries, as well as how libraries can integrate them. The paper concluded by stating that there is need for management of libraries to ensure internet connectivity in their libraries, which is a prerequisite for the use of these applications.
\end{abstract}




\section{Introduction}

Social media and library services points of convergence is the interlinking of library services and social networking tools like facebook, Blog and a host of others made feasible with the development of the internet. The internet as a new creative outlet has altered the Economics of information production, increase the democratization of media production and led to changes in the nature of communication and social relationships, changes in the way users produce, distribute, way users produce, distribute, access and re-use information knowledge and entertainment, potentially given rise to increased user autonomy, increased participation and increased diversity.

Social media is one of internet enable platforms for exchange of information and social interaction. It is a tool that facilities communities of information through human interaction. According to Osahenye (2011), social media is online networking via such websites as Twitter, Linkedin, facebook, Youtube, Flickr, Myspace, Ning, Digg, and others. According to Osahenye, these websites work via web 2.0 technologies which allow internet users to easily save, publish, post and share any information that could be sent to a heterogeneous audience instantaneously. Web 2.0 does not only allow the users to post comments, video and pictures, it is also interactive and elicits spontaneous response to disseminated uncensored information. Rehman and Scholar, (2011) stated that the World Wide Web provided the base for these web 2.0 applications to create a new communication environment. Web 2.0 applications to create a new communication environment. Web 2.0 applications are socially rich and aid in community building. Boating, Mbtika and Thomas as cited in Rehman \& Scholar (2011) opined that these socio-technological innovations have enabled inter activity and gathering of knowledge through experience and practice on a global scale. According to them, the concept of collaborative work, social networking and the ease in the usage of these applications have brought significant changes in the Internet and the style of Internet surfers in the world. The popularity of social networking application, blogs and sharing of media have also changed the way and behavior of user of libraries all over the world. According to Mcmanns (2009), many academic libraries in the United States are beginning to leverage the power of these services to provide better and more relevant services to their patrons. According to him, they are doing so by integrating web 2.0 services into their web presence. Web 2.0 services are becoming part of library patrons'

primary activities online when accessing information and libraries need to stay vital to their patrons by using these same services. The implementation of these services has huge implication for how libraries are now and in the future will stay relevant to their 
communities, and how they will face the next generation of new information technology users (Mcmanns, 2009). Sperring as cited in Mcmanns (2009) observed that library users are there for one common reason, and this is to find information. According to him, if libraries don't provide them with that, they will go elsewhere to find it.

The integration of these services into the library paradigm of services is known as library 2.0. According to Maness (2006), library 2.0 is the application of interactive, collaborative and multi-based technologies to web-based library services and collection. According to Nielsen company, online measurement for quarter four 2010, 74 percent of the world's internet population visit a social networking/blogging site and this site is visited by users on average of six hours monthly. Facebook alone recorded a staggering 600 million users worldwide by January, 2011 (Osahenye, 2011). The combination of all the subscriptions for all the social media platforms will no doubt give a surprising figure in relation to the world population. These social media platforms including Blogs, Wiki, Facebook, Myspace, Instant Messaging, Podcasting, Twitter Youtube, Flicker, RSS, feeds, Ning, etc, have therefore proved veritable platforms for development of library services. A brief description of the social media platforms and bow libraries can integrate them for services are hereby enunciated below.

\section{Concept of Social Media}

Social media according to Khan \& Bhatti, (2012), is a broad term that covers a large range of websites which enable people to interact with other visitors. According to Osahenye (2011), social media is online networking via such websites as Twitter, Linkedin, Facebook, Youtube, Flickr, Myspace, Ning, Digg and others. According to him, these websites work via web 2.0 technologies which allow internet users to easily save, publish, post and share any information that could be sent to a heterogenous audience instantaneously. According to Khan and Bhatti (2012), the whole business of libraries is about connecting people with information, and this is what social media is really all about. It is therefore being used by millions of people in the world. Statistics of social media usage shows that there are 750 million active facebook users, 115 million Linkedin users, 50 million Myspace users, 24 million pages of Wikipedia, .5billion + images on Flickr, 2.9 billion hours of Youtube watching per month, 25 million use google plus and 300 million twitter users posting over 7000 tweets per second (Khan \& Bhatti, 2012). Social media is reputed to grab the attention of new users, helps in distance learning, knowledge sharing and locating information. 


\section{Social Media Technologies and Benefits to Libraries: BLOGS:}

The word, blog is short form of weblog. It refers to a particular category of website where the content is presented in a continuing sequence of dated entries, displayed in reverse chronological order and the nearest entry is at the top of the webpage. According to Anaduaka and Udem (2011), it can be updated hourly, daily, weekly or monthly. Also Mannes (2006) pointed out that blogging is an easy process of publishing one's ideas on the web, and getting comments and inputs from other users of the web. According to Ibe (2011), there are many different types of blogs, differing not only in the type of content, but also in the way that content is delivered or written. As a result, there are personal blogs, corporate and organizational blogs; by genre, which focus on a particular subject such as political blogs, education blogs, travel blogs etc by media type, for example a blog comprising video is called Vblog, one comprising photo, is called photoblog and blogs by device used to compose it, for example, moblog is one written by a mobile device.

\section{Blog as Platform for Library Services}

The immense ability of blog to transmit information has since been adopted by libraries to reach out to library clientele. According to Anaduaka and Udem (2011), librarians can use blogs as a platforms for information services, as a library service, as a feedback tool, and as a professional awareness tool. As an information service, librarians use blogs to inform clients of changes and additions to library services and collections, news and current events. Here it is also used as platform for interaction between the library and its users. This is a forum where inputs and suggestions for contents are welcome from the community.

As a library service, blogs can be used by Library and Information Service (LIS) professionals to list new books, videos, CDs/DVDs, as they are added to the collection (Anaduaka \& Udem 2010). Blogs can be used to review new titles and link them to relevant internet sites, to start an online discussion, provide links to author interviews, list book award announcement. According to Orji as cited in Onwubiko (2010), blogs can be used to promote and market the library's collection, services and programmes, so as to draw people into the library. Announcement of library activities and calendar of events can be disseminated via blogs. 
As a feedback tool, blogs encourage valuable feedback from readers via the comments link. Library patrons can provide information about their library experiences and guide librarians to improve the performance of the libraries (Anaduaka \& Udem, 2010). Through the free use of blogs, it is possible to create a virtual environment where all comments are respected, appreciated and taken into consideration (Onwubiko, 2010).

As a professional awareness tool, blogs can be used as a current awareness and professional aids for keeping the librarians up to date in their field. Blogs help users stay ahead of changes in technology and in the library profession. Cohen (2010) averred that librarians need to stay ahead to justify their existence and so that customers will look to the library as a place of currency, and not just archive. Hane (2001) opined that blogs are natural for librarians. According to him, librarians all over the world are using blogs for easy dissemination of information to the targeted users. Clyde (2004) stated that blogs are the fastest growing medium of information over World Wide Web. According to him, blogs are created as single person effort, but noted that some blogs are created and published as co-operative or group projects. According to Clyde (2004), most librarians are maintaining their blogs by collaborative efforts.

\section{Wikis}

Wikis are another example of collaborative creative work. Multiple users from all over the world can build a knowledge base by using this application. Wikipedia is a great example of this kind of collaborative work. Lombardo as cited in Mcmanns (2009) stated that the wiki has become a popular collaborative tool, providing accessible online space use to develop and share documents, as well as to browse and search information. Ukoha (2010) opined that wiki is software often referred to as wiki engine that allows users to freely create and edit webpage contents, using any web browser. According to Onwubiko (2010), wiki differs from blog in that a person can add information, and also change what has already been published.

\section{Wikis as Platform for Library Services}

A library wiki, as a service, can enable social interaction among librarians and patrons, essentially moving the study group room online (Maness, 2006). According to him, wikis can be used to create help files, tutorials, with the help of users in libraries. Wikis allow users to change and update factual information as they see fit, filling in those knowledge gaps for others. Several librarians have adopted the wiki tool in the provision of services. According to Onwubiko (2011) at the National library of 
Singapore, a wiki platform was created for the librarians to collaboratively and concurrently provide answers to the users' enquiries. According to her, it allows any staff to tap on the collective wisdom of the communities of subject librarians and provides quality answers to their queries. A wiki can be used for research. According to Onwubiko (2010), the Ohio University created a business wiki to assist business researchers with their research. Casey (2010) opined that the business wiki contains a variety of contents including information about reference books, websites, research guides, how to document and more. Wiki allows librarians to determine which contents are used most, thereby influencing the type of content to focus on. Wikis allow librarians to communicate internally by providing a space where the entire library personnel can stay informed on what is happening, or to update manuals and document for library use. Mannes (2006), concluded that wikis are the mix of many other technologies like messaging, blogging, streaming and media and tagging.

\section{RSS Feeds}

An RSS feed is another web 2.0 application which helps users to bring the updates and feeds from other websites. It stands for rich site summary or really simple syndication. According to Linh (2008), it is a very simple tool to bring the latest stories, updates from news groups, magazines, journals and blogs. It creates a feed from a site that readers can then add into an aggregator to create one point of access from many sources. According to Onwubiko (2010), RSS services consist of a list of items, each of which usually includes a description, and a link to a webpage. It allows users to receive contents from sources such as news organization blogs and any webpage that changes its contents frequently. The ability of the RSS to funnel through many types of technology and present the information in any easy to read format is a good attribute of RSS.

Library \& Information Science Departments according to Khan and Bhatti (2012), can use RSS to communicate departmental news with their students, announcing staff changes, new courses or any other news that is relevant and of interest to the student population. Librarians can use RSS to keep library users up to date with what is new, without requiring them to visit the website. Librarians can also use RSS to inform users about author visits to the library provide information about upcoming book sales or promote classes or programmes. Librarians can use RSS to inform users about new arrivals, exhibitions, or other events of the library. 


\section{Instant Messaging}

Instant messaging as noted by Rehman (2011), is also a very useful tool that will help library professionals to provide enhanced library services. Instant messaging is used for online reference services for libraries. Currie (2010) opined that librarians can provide online reference services through instant messaging by employing staff at public desks during nights and weekends when the library is closed for other services. Turbar as cited in Onwubiko (2010) defined instant messaging as online real time communication between two or more people who are connected to the internet. Anaduaka and Udem (2010) explained that instant messaging allows online communication between two or more people using typed text sent via computers in real time. The use of instant messaging in libraries provides a virtual reference service, increases the availability of services to clients at no cost to the library. It offers an alternative method of communication to clients and brings the library to the community. According to Mcmanns (2009), instant messaging allows library patrons remote access to librarians while conducting their research. According to him, while it might be just as easy to ask a question face to face, accessing a librarian remotely and afford the patron the use of their own computer and instant access to the suggestions made by the librarian. Harinarayana (2010) reported a study of 100 university librarians that showed that instant messaging features have extensively been used in libraries to provide quick online reference service. Concurring, Maness (2006) noted that ask a librarian services is a typical example of the use of instant messaging.

\section{Podcast}

A podcast is an audio program distributed over the internet which subscribing users can download onto their personal computers or portable music players. Stephens as cited in Mcmanns (2009) explained that podcasting is a form of audio blogging where an audio file such as an interview or a presentation is embedded in blog or webpage, and which can be downloaded to a patron's computer or Mp3 player for later listening.

Podcast is now used by librarians for book talk; especially in public libraries (Onwubiko, 2010). It is equally used by librarians in storytelling. Some librarians have also used podcast to provide library instructions and information literary programmes. According to Anaduaka and Udem (2010), librarians use podcast as training tools for database and online library resources. They use it to give weekly updates about what is going on in the library and community. They provide library tours on podcast. They review new books and follow up interviews with patrons who have read the books. 
Examples include the V ALA 2006 conference which has podcast of all papers delivered (www.vala.org.au/vala2Q06/prog2006.htm).

\section{Youtube}

Youtube is a video-sharing website on which users can upload, share and view videos. It uses adobe flash video technology to display a wide range of user generated video contents including video chips, television chip, music videos. Youtube is used by both registered and unregistered users (Onwubiko, 2010). Registered users are allowed to upload an unlimited number of videos while unregistered user can only watch the videos. Libraries are using vodcast to illustrate what the library has done and to attract the community to attend future programmes. Simply put, it serves as a marketing tool for libraries. According to Khan and Bhatti (2012), Youtube can be used to share videos, conferences, workshops and library event.

\section{Facebook}

Facebook has attracted a lot of attentions and can be termed a household phenomenon especially with its capacity to effect spread of information worldwide in split seconds. According to Osahenye (2011), in the month of January, 2011, facebook recorded a staggering 600 million subscribers worldwide. Osahenye further noted that facebook was originally intended to connect university students, but quickly spread throughout the confines of campuses, and is now the world's largest social networking website. Facebook provides a virtual community for people interested in a particular subject or just to network and stay together. Members create their own online profile with biological data, pictures, likes, dislikes and any other information they choose to post. They communicate with each other by chat, instant messaging, video and blogs and the service typically provides a way for members to contact friends. To generate buzz, users could tag notes, pictures and videos with relevant keywords and allow it to be searchable in the sites mentioned; files could be saved into windows media video which can be uploaded to youtube.

Facebook has been latched on by marketers, researchers, students and even politicians, such as the highly cited electioneering campaign success of Barack Obama in 2008. It presents an amazing opportunity to reach market influencers, prospective and existing customers, which invariably boost brand awareness (Osahenye, 2011). These attributes can be harnessed by libraries for marketing of library services, brand/programme awareness and reference services. 


\section{Linkedin}

Linkedin is popular among professionals like librarians and have, proved a veritable platform for exchange of views, news updates and social interaction. It can be adopted by libraries for such other services as obtainable in other web 2.0 enabled social media technologies. According to Khan and Bhatti (2012), professional networking site like Linkedin can be used by the libraries to create professional connections and to market library services among other professionals working in different libraries of the world also solicit their ideas and professional experience.

Other social media sites include twitter, myspace, 2go, meabo.com and a host of others too numerous to contain in this paper.

\section{Need for the Social Media in Libraries}

Having elaborated on most of the social media platforms, a lot of benefits and potentials which libraries can latch on to improve information and reference services and of course, touching on the needs of users has been established. Sparring as cited in Mcmanns (2009) opined that library users are there for one common reason and which is to find information and if libraries do not provide them with that, they will go elsewhere to find it. Libraries are charged to harness all avenues that will appeal to the needs of their users. The adoption of social media applications is very high because, according to Schneckenberg (2009) they are easy to use, intuitive and enable the direct and immediate online publication and distribution of user-content. Moreso, according to Rehman (2011), as most web 2.0 applications are offering services free of cost, libraries with low budgets can get the benefits from these technologies. It is necessary also to focus on the current and upcoming generations while designing library services. According to Khan and Bhatti (2012), libraries can promote services, collections, events and resources by using social media. Social media provides more opportunity to research your community, target specific audiences and give them a chance to interact with your library. Social media can be used for fund raising, to spread news and services alerts, to provide quick update to online users, push library news and press release among online users, and helps in maintaining closeness with users (Khan \& Bhatti, 2012). Libraries can share and upload the pictures of different library events and services using flicker. Libraries can use facebook to share the information about their new arrivals and editions of books. According to Khan \& Bhatti (2012), different applications of social media are useful for libraries to obtain their patrons' feedback, and to ensure the maximum engagement of their users in the production of 
their products and services. It is a fine tool for marketing library services among new generation users and to create user-centered libraries. Rehman (2011) noted that social media application will help to refine the quality of service delivery to the users in their own communities. According to him, libraries can design attractive services using these social media applications without spending huge budgets for online hosting and storage. Due to changing needs of users, libraries need to be changed accordingly, (Khan \& Bhatti, 2012). Reasons also abound why libraries should adopt the use of social media in services. Such reasons include communication, responding to positive/negative feedback, marketing advertising and need to understand users better.

\section{Communications}

Social media is another way that you can get into contact with your patrons and it is necessary to recognize the new trend.

\section{Responding to Positive/Negative Feedback}

According to Burkhardt (2009), when people are portraying your library in bad light on the web and in different social media channels, you can only influence the message if you are also on the web. One of the most important tenets of customers' services is to be responsive to your users concerns or praise. Recognize them and show that you are interested in and care about their opinions.

\section{Marketing/Advertising}

Your library likely already markets its services or events using traditional media, fliers, and bookmarks, announcements in calendar of events, newspaper aids, and press releases and so on. Social media is simply another form of media that you can use to get your message across millions of people that use social media networks, and you are missing out on a lot of people or eyes if you eschew social media.

\section{Understanding Users Better}

Social media allows conversation with your users, and these conversations often reveal important insights, simply talking with people allows you to get to know them better and more importantly, serve them better. According to Burkhrdt (2009), have conversation with patrons both in person and through social media and you will be surprised at what you learn. 


\section{How Can Libraries Integrate Them?}

Arif and Mahmood (2010) noted that the acquisition of internet skill and the availability of internet enabled device are the main factor towards adoption of social media technologies in the libraries. According to Rehman (2011), the basic task is to introduce services in libraries that can be refined using these technologies, while focusing on the need of the current and upcoming generations while designing the services. This is what Mcmanns (2009) referred to as keeping vision of services in order to keep up with users' needs. Look at what interest your patrons. Think also beyond the library building.

Depending on the type of library, the audience may be larger or small, homogenous or varied. The audience may consist of undergraduates, postgraduates, academic staff, alumni, library staff, external visitors, the media, tourist and a range of random other people. Look also at what contents you already have that can quickly and easily be loaded into social media sites, examples include, PowerPoint presentations, photos, videos podcast, a blog for your newsletter, alerts, current awareness, (Mcmanns, 2009). Once your content is loaded, you can start looking at the options for sharing and embedding in other applications example, slide share presentation in your blog, webpage, facebook page and so on. Rehrnan (2011) concluded that information professionals should think about their users' need which they want to fulfill with these applications and then select a feasible service accordingly. This is because certain applications are best suited for certain specific needs.

\section{Conclusion}

There is no gainsaying the fact that the old traditional environments have given way to new technologically driven information environment. Having highlighted the abundant benefits accruable to libraries through social media application, as well as limitless potentials for growth, this paper enjoins libraries to adopt them in services. This paper has also highlighted the need for management of libraries to ensure internet connectivity in their libraries, which is a prerequisite for the use of these applications. Social media services cannot be feasible without internet, and users cannot access what is not available. 


\section{References}

Anaduaka, A. \& Udem, O. (2010). Services offered by library and information science professionals using the internet: unpublished seminar topic, Dept of Library Information Science, Unizik Awka.

Arif. M. \& Mahmood, K. (2010). The changing role of librarians in the digital world: adoption of web 2.0 technologies in Pakistani libraries. Paper presented at the $76^{\text {th }}$ IFLA general conference and assembly, Gothenburg, Sweden.

Burkhardt, A. (2009). Four reasons libraries should be on social media. Retrieved from http://andtiburkhardt.com2009.08/25/four-reason-librariesshouldbeonsocialmedia.

Casey, M. (2006). Library crunch: bringing you a library 2.0 perspective. Retrieved from http.//ww.librarncrunch.com.

Clyde, L.A. (2004). Library weblogs: Library management 25,4150, pp. 183-189.

Cohen, S.M. (2003). Keeping Current: advanced internet strategies to meet library and patron needs. Chicago: American Library-Association.

Currie, J.P. (2010). Web 2.0 for reference services, staff training and communication. Reference Services Review, 38(1), pp. 52-157.

Hane, P.J, (2001). Blogs are natural for librarians, newslink, 1.

Harinarayana, N.S. (2010) web 2.0 features in university library websites. The electronic library, 28(1).

Ibe, P. (2010). Blogs: unpublished seminar topic; Dept of library \& information science, Unizik Awka.

Khan, S.A. \& Bhatti, R. (2012). Application of social media in marketing of library and information services. A case study from Pakistan. Webology 9(1), Article 3. Available at http.//www.weboloQy.org/2012/v.9nl/a.93 html.

Maness, J.M. (2006). Library 2.0 theory: web 2.0 and its implications for libraries: webology 3 (2). Retrieved from http://www.webology.ir/2006/q=Unk:weboloc]ij.ir.

Mcmans, B. (2009). The implications of web 2.0 for academic libraries. Electronic of academic and special librarianship 10(3).

Onwubiko, J. (2010). Library 2.0 unpublished seminar topic; Dept of library \& information science, Unizik, Awka. 
Osahenye, K. (2011). The social media challenge. The Guardian, Friday, February 25, p. 52.

Rehman, A.V. \& scholar, M.P. (2011). Web 2.0 applications in libraries. Library philosophy and practice. Retrieved from $h t t p i / / u n l l i b . u n i e d u . d p p l$.

Ukoha, O.I. (2010). Current technologies in library and information services: issues and challenges. Paper presented at the international workshop on current trends and technologies in library and information services in the 2Ft century, $26^{\text {th }}$ March. 